Copyright (C) 2017 by Academic Publishing House Researcher

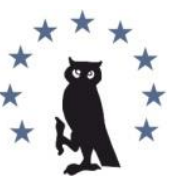

Published in the Russian Federation

European Researcher. Series A

Has been issued since 2010.

ISSN 2219-8229

E-ISSN 2224-0136

2017, 8(2): 78-87

DOI: 10.13187/er.2017.2.78

www.erjournal.ru

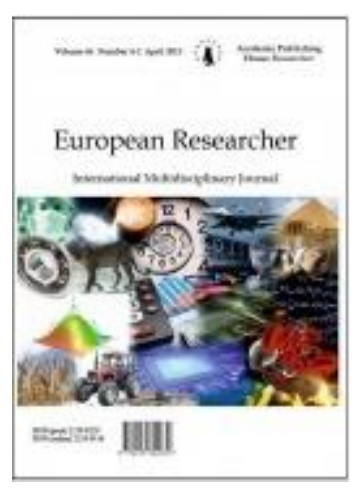

UDC 33

\title{
Human Resource Management Practice and Organizational Performance: Case Study from Hormuud Telecom in Mogadishu-Somalia
}

\author{
Abdulkadir Mohamud Dahie ${ }^{\mathrm{a},{ }^{*}}$, Raqia Ahmed Mohamed ${ }^{\mathrm{b}}$ \\ ${ }^{a}$ Kampala University, Uganda \\ b Faculty of Humanities, University of Somalia, Somalia
}

\begin{abstract}
Organizational performance is getting more and more important, especially in a market with greater competition and dynamic. Organizational performance is measured through different indicators. It guarantees the continuity of the organization to be competitive in a global marketplace. Normally, the implementation of performance indicators achieved through human resources. Human resources are the key for keeping the organization in the market. These human resources need to be managed effectively to achieve the required performance of the organization. It is necessary to manage strategically the human resources and to adapt at its strategy with organizational strategy. The aim of this study is to investigate the influence of recruitment and selection on organizational performance, to examine the role of compensation and reward on organizational performance as well as the effect of performance appraisal management on organizational performance at Hormuud Telecom in Mogadishu-Somalia. The researcher utilized convenient sampling to collect 100 questionnaires from Hormuud Telecom in Mogadishu, Somalia. These respondents were provided a questionnaire with four main construct which measuring recruitment and selection, compensation and reward, performance appraisal management and organizational performance. However, using correlation coefficient, the study found that organizational performance (Dependent variable) had significant positive influence with three dimensions of independent variable. The result of regression analysis found that three constructs had statistically significant, positive, and straight effects with organizational performance.
\end{abstract}

Keywords: human resource management practice, Recruitment and selection, Compensation and reward, Performance appraisal management, organizational performance.

\section{Introduction}

In recent years, firms have been urged to adopt a variety of performance-enhancing or progressive HRM activities to increase their market share and improve their competitiveness in the global market because HRM plays a critical role in firms' success by having considerable influence on organizational performance. Therefore, strategic HRM is expected to help firms achieve better organizational performance. Abundant studies have documented the significant relationship

\footnotetext{
${ }^{*}$ Corresponding author

E-mail addresses: Dahie@uniso.edu.so (Abdulkadir Mohamud Dahie), rakia@uniso.edu.so (Raqia Ahmed Mohamed)
} 
between HRM practices and organizational performance. Jacob \& Jolly (2012) studies demonstrated that high commitment levels on behalf of the workers are possible when appropriate HRM practices are used. Katou (2008) noted that HRM practices have direct effects on employee attributes such as skills, attitudes, and behaviors (the so-called HRM outcomes), which in turn can enhance organizational performance. Pfeffer (2000) observed that HRM practices reflect an essential method for sustaining organizational performance.

Although, it is generally known that HRM practices are positively related to organizational performance, there remains a need for more robust evidence supporting the HRM-performance relationship in various cultural contexts (Yazam \& Ahmid, 2011). Here another issue is that many researchers have questioned this relationship (Katou, 2008; Gerhart, 2005). Based on these theorems, Becker and Gerhart (1996) suggested some intermediary steps- some moderators' existing in the relationship. Previous studies of HRM practices and organizational performance have found CEO support to be a critical factor influencing the successful implementation of HRM practices and thus organizational performance (Smith, 1991; Martinez, 1993; Seal, 1991; Williamson, 1993). Therefore, this study examines whether there is a positive relationship between HRM practices and organizational performance and whether CEO support moderates this relationship.

As indicated earlier, several studies have tested the relationship between HRM practices and organizational performance and generally provided support for this relationship. In fact, recent studies have gone beyond the analysis of the relationship between various HRM practices and organizational performance, identifying the mechanisms through which HRM practices influence organizational performance (Boselie et al., 2005; Collins \& Smith, 2006; Hailey et al., 2005). Recent reviews of research on this relationship have questioned the methodological rigor of previous studies (Wall, Wood, 2005). This suggests that it is premature to conclude a positive relationship between HRM practices and organizational performance.

In today's competitive and rapidly changing business world, organizations especially in the service industry need to ensure maximum utilization of their resources to their own advantage; a necessity for organizational survival. Studies have shown that organizations can create and sustain competitive position through management of non-substitutable, rare, valuable, and inimitable internal resources (Barney, 1991). HRM has transcended from policies that gather dust to practices that produce results. Human resource management practices has the ability to create organizations that are more intelligent, flexible and competent than their rivals through the application of policies and practices that concentrate on recruiting, selecting, training skilled employees and directing their best efforts to cooperate within the resource bundle of the organization. This can potentially consolidate organization performance and create competitive advantage as a result of the historical sensitivity of human resources and the social complex of policies and practices that rivals may not be able to imitate or replicate their diversity and depth.

Armstrong (2009) defines Human Resource Management (HRM) as a strategic and coherent approach to the management of an organization's most valued assets; that is, the people working there who individually and collectively contribute to the achievement of its objectives. Moreover, Human resource management practices can be defined as a set of organizational activities that aims at managing a pool of human capital and ensuring that this capital is employed towards the achievement of organizational objectives (Wright, Boswell, 2002). The adoption of certain bundles of human resource management practices has the ability to positively influence organization performance by creating powerful connections or to detract from performance when certain combinations of practices are inadvertently placed in the mix (Wagar, Rondeau, 2006).

In fact, Ahmad and Schroeder (2003) found a positive influence of human resource management practices (information sharing, extensive training, selective hiring, compensation and incentives, status differences, employment security, and decentralization and use of teams) on organizational performance as operational performance (quality, cost reduction, flexibility, deliverability and commitment). In furtherance of this assertion, Sang (2005) also found a positive influence of human resource management practices (namely, human resource planning, staffing, incentives, appraisal, training, team work, employee participation, status difference, employment security) on organization performance.

The concept of Human Resource Management was first defined by Bakke (1966) who said that the general type of activity in any function of management is to use resources effectively for an 
organizational objective. The function which is related to the understanding, maintenance, development, effective employment and integration of the potential in the resource of "people I shall call simply the human resources function. However, HRM emerged fully fledged later when the Michigan „matching model (Fombrun et al., 1984) and what (Boxall 1992) calls the Harvard framework developed by Beer et al (1984) made statements on the HRM concept revealing the need to take HRM beyond just selection and compensation to broader issues that demand more comprehensive and more strategic perspective to an organization's human resources

The term Human Resource Management (HRM) is a strategic, integrated and coherent approach to the employment, development and well-being of the people working in organizations. To Boxall et al, (2007), it is the management of work and people towards desired ends. Som, (2008) described HRM as carefully designed combinations of such practices geared towards improving organizational effectiveness and hence better performance outcomes.

\section{Recruitment and Selection}

Recruitment which is the process of generating a pool of capable people to apply for employment to an organization and selection which is the process by which managers and others use specific instruments to choose from a pool of applicants a person or persons more likely to succeed in the job(s) given management goals and legal requirements ${ }^{\text {ec }}$ Bratton and Gold (2007, p. 239). Recruitment and selection can play a pivotal role in shaping an organization's effectiveness and performance, if organizations are able to acquire workers who already possess relevant knowledge, skills and aptitudes and are also able to make an accurate prediction regarding their future abilities. Performance improvement is not only a result of well-functioning system but also depends on effective human resource strategies that succeed in recruiting and maintaining a committed and motivated workforce (Al-Ahmadi, 2009).

Recruitment and selection has become ever more important as organisations increasingly regard their workforce as a source of competitive advantage. It is often claimed that selection of workers occurs not just to replace departing employees or add to the number but rather aims to put in place workers who can perform at a higher level and demonstrate commitment (Ballantyne, 2009).

\section{Compensation and reward}

Compensation processes are based on compensation philosophies and strategies contained in the form of policies, guiding principles, structures and procedures which are devised and managed to provide and maintain appropriate types and levels of pay, benefits and other forms of compensation. This constitutes measuring job values, designing and maintaining pay structure, paying for performance, competence and skill and providing employee benefit. However, compensation management is not just about money, it is also concerned with that non-financial compensation which provides intrinsic or extrinsic motivation (Bob, 2011). Compensation has a motivational effect and therefore implies that having a compensation structure in which the employees who perform better are paid more than the average performing employees is vital to enhancing organizational performance (Hewitt, 2009). The growing recognition and consensus that compensation promotes productivity is consistent with the early work of Peter Drucker (1956) that states "happy workers are productive workers.

\section{Appraisal/Performance Management}

Performance appraisal of employees is the systematic evaluation of employees" performance and potential for development during a certain period of time by supervisors or others who are familiar with their performance. It is one of the oldest and widely used management practices. Performance appraisal is an indispensable tool for an organization because the information it provides is highly useful in decision making regarding issues such as promotion, merit increases transfer, discharge, training and development. Not only is performance appraisal useful for the above issues, it may also increase employee's commitment and satisfaction Wiese and Buckley, (1998). However, there has been a great realization that it is more important to focus on defining, planning and managing performance than merely appraising performance Pareek and Rao, (2006). The increased competitive nature of the economy and rapid changes in the external environment has forced many organizations to shift from reactive performance appraisals to proactive performance management to boost productivity and improve organizational performance (Nayab, 
2011). Prasad (2005) defines performance management as the process of planning performance, appraising performance, giving its feedback, and counseling an employee or teams to improve performance. As Armstrong (2006) put it, performance management is a systematic process for improving organizational performance by developing the performance of individual and teams. Performance management is one of the most important developments in the field of HRM probably propelled into visibility in the early $1980^{\circ \mathrm{s}} \mathrm{s}$ as a result of the growing importance of total quality management.

Researchers have different opinions of what performance is. Organizational performance continues to be a contentious issue in the management research circles. Javier (2002) equates performance to the famous $3 \mathrm{Es}$; economy, efficiency and effectiveness of certain programmed of activity. According to Richard et al (2009) organizational performance encompasses three specific areas of firm outcomes; financial performance (profits, return on assets, return on investment, etc), product market performance (sales, market share, etc.), and shareholder return (total shareholder return, economic value added, etc.). Organizational performance is the organization's ability to attain its goals by using resources in an effective and efficient manner Daft (2000). We can put organizational performance as the actual output or results of an organization as measured against its intended outputs, that is; goals and objectives. Performance should not be confused with productivity; according to Ricardo (2001), productivity is a ratio depicting the volume of work completed in a given amount of time. Performance is a broader indicator that could include productivity as well as quality, consistency, effectiveness, efficiency and other factors.

Several researches have been conducted various methods to evaluate organizational performance (Wong \& Wong, 2007; Prajogo, 2007; Moneva, Rivera-Lirio, \& Mun oz-Torres, 2007). Steer (1975) conducted a general study on 17 patterns of organizational productivity and merged the components of these different researches relating to the evaluation of organizational performance. Organizational performance is a sign of the capacity of a company to efficiently achieve independent goals (Venkatraman \& Ramanujam, 1986). After examining ten various kinds of assessments, they made the findings general into three aspects: financial performance, business performance and effective organization. A system was developed by Delaney and Huselid (1996), involving two elements for estimating market performance: market share and earnings ratio. Moreover, a fully completed set of dimensions for human resource performance has been suggested by Huselid, Jackson, and Schuler (1997).

\section{Literature review}

The purpose of this paper is to evaluate the effects of strategic human resources management (SHRM) practices on the primary measures as expressed by the Organizational Climate and the secondary measures as expressed by the organizational performance, and to find out the effect of the Organizational Climate on the organizational performance of Nigerian oil and gas companies. To achieve these objectives, an empirical study was conducted via the administration of 450 selfadministered copies of questionnaire to a randomly selected senior and management staff often (10) Oil and Gas Companies, that have implemented SHRM in Nigeria. Findings based on the survey revealed that strategic human resources management (SHRM) practices positively affected both performance measures in the Nigerian oil and gas companies. Specifically, apart from career planning system, in descending order, the results suggest that, Strategic HRM alignment, training and development, Compensation System, Selection System, and Performance appraisal system and are the key SHRM practices that influenced both organizational climate and performance in the Nigerian oil and gas industry (Dele et al., 2015)

The purpose of this paper is to measure the impact of HRM on organizational Performance in the context of Greece. Data were collected from 178 organizations using a questionnaire survey in the Greek manufacturing sector, and analyzed using the 'structural equation modeling' methodology. The results indicated that the relationship between HRM policies (resourcing and development, compensation and incentives, involvement and job design) and organizational performance is partially mediated through HRM outcomes (skills, attitudes, behavior), and it is influenced by business strategies (cost, quality, innovation). Thus, the contribution of this study for academics and practitioners is that HRM policies associated with business strategies will affect organizational performance through HRM outcomes (Katou, 2008). 
The aim of this study is focused on the impact of the strategic management of human resource in achieving organizational performance. This study was conducted through the collection and analysis of various publications on this field. The secondary source, refer various publications that have been made in this area about empirical studies, various academic debates and analyzes the different findings. The study found that the potential use of skills, knowledge and competencies of employees in the organization would make possible the realization of organizational performance. Basically, it is also confirmed by other research that strategic management of human resources has an impact on organizational performance (CANIA, 2014).

This paper aims to fill the gap in the organization performance literature by highlighting the contribution of HRM in influencing business organizational performance through its intermediate effect on innovation and environmental management. Data were collected from 140 organizations using a questionnaire survey in the Greek manufacturing sector, and analyzed using the 'structural equation modeling' methodology. Human resources are vital for firms to achieve advanced innovations and sustainable performance in the ever-changing environment. The standpoint of this study emphasizes the important role of innovation performance and environmental performance when addressing the link between human resource management and organizational performance (Wong et al., 2013).

The aim of this study was to identify commonly HRM practices effect on Malaysian private companies' performance. Data for this study was gathered by primary data collection method through personal administered questionnaire. Due to the cost constraint a convenient sample of 159 private companies were chosen for this research. One trained data collector approached potential respondents in randomly selected private business organization in Selangor in Malaysia. After assisting a respondent in completing a survey, the data collector would then approach the next available person and resume the screening process. Regression results showed that training and development, team work, compensation/incentives, HR planning, performance appraisal, and employees security have positive and significant influence on business performance with the exception for compensation/incentives and employees security (Abdullah et al., 2009).

This study investigated the impact of three HR practices on the perceived performance of university teachers in AJK. Responses from113 respondents were used to analyze the impact of selected HR practices (compensation, performance evaluation, and promotion practices) on the employee's performance. Pearson correlation and regression have been used to find the association among variables and impact of three independent variables on the dependent variable of perceived performance of university teachers. The result of the study showed that the compensation practices in relation to the employees' performance are significantly positively correlated whereas the performance evaluation and promotion practices have insignificant relationship with the performance of university teachers in AJK Pakistan (Ahmad, Shahzad, 2011).

This study was conducted to determine the impact of HRM practices on employee's performance in the Textile industry of Pakistan. Random sampling technique was used to collect data for this research study. A questionnaire based on 34 items was distributed among 68 employees of textile industry for data collection. To check the association between HRM practices and employee's performance, Pearson correlation statistical technique and regression analysis was applied on the data. The results indicate that HRM practices Compensation, Career Planning, Performance Appraisal, Training, and Employee Involvement have a positive impact on employee's performance. Hence, it is proved that independent variables contribute positively towards change in the dependent variable. (HASSAN, 2016).

The aim of this article is to review the research previously carried out by various researchers in the field of Human Resource Management Practices and Organizational Performance. For the present study, authors have reviewed books, research journals and thesis available on internet. The work includes various major empirical studies based on impact and linkages between HRM Practices and Organizational Performance. From the detailed literature review, we can conclude that various HR practices have positive influence or impact on operational and financial performance of the organization (Trivedi, Raval, 2015).

This study intends to examine the effects of various HRM practices on organizational performance and the moderating effect of CEO support on the relationship between HRM practices and organizational performance. This study employed a survey on 215 Chinese firms. The results indicate a positive relationship between HRM practices and organizational performance and verify 
the moderating effect of CEO support on this relationship. This study is the first one on demonstrating the moderating effect of CEO support on the relationship between HRM practices and organizational performance in the context of Chinese firms (Rhee et al., 2014).

This study examined Effectiveness of HRM strategy and practices are not established in public organizations of Pakistan. Getting the best and desired outcome is the gap and has been a point of concern for organizations in Pakistan irrespective of size and sector. Purpose of this conceptual paper is to typify different approaches of HRM and look for best fit HRM model to implement effectiveness of HRM practices and generate desired organizational performance in local conditions of developing countries. The literature on three famous HR approaches and models was reviewed and a best fit HRM model is proposed that postulates mutually dependent relationship between HRM practices and organizational performance that aims to maximize the effectiveness of HRM practices. Need is recognized for developing trusted relationship between management and employees in Pakistani organizations. The paper presents a conceptual trust-oriented HRM model that takes into account the Pakistani mindset that is inconsistent at one time and vibrant at the same time. This research study provides a framework for HR specialists to create and sustain networks and connections with people in a more trusted environment (Arshad et al., 2014).

The purpose of this study is to narrow this gap in the research. The study, moreover, attempts to investigate the connections amid organizational culture, knowledge management, and organizational performance. The research utilizes causality models and suggests a conceptual schema subsequent to a comprehensive analysis of the literature linked to human resource management field. A sample of 203 human resource directors working in large organizations in the Eastern Region of Saudi Arabia is used. The confirmatory factor analysis and SEM are used to analyze and approve the proposal of the conceptual schema. The study illustrates that human resource management practices is an important ancestor of organizational culture, knowledge management, and organizational innovation, which have in turn a positive link to organizational performance. The research attempts to draw concentration to some of the elements, playing the function of arbitrator amid human resource management practices and organizational performance. The study is unique because it is initially conducted to urge the impacts of some important related patterns such as human resource management practices, organizational culture, knowledge management and organizational innovation, and organizational performance (Albahussin, El-garaihy, 2013).

This research looked at the impact of HRM practices on organizational performance in the case of some rural banks in the Ashanti region of Ghana. Research over the years, has established significantly a positive correlation between HR practices and organizational performance. The objectives of the study were to examine the general HR practices and programs of the rural banks, evaluate the perceptions of employees on HR practices and programs of the rural banks and establish the impact of properly managing human resources on the performance of these rural banks. This study surveyed four branches each of four rural banks with total respondents of 150 made up of 40 managerial employees and 110 non-managerial employees. The response rate was $98.66 \%$ which represented 40 managerial employees and 108 non-managerial employees. The study employed two sets of 8 and 10 HR practices categorized questionnaires for managers and employees respectively. Purposive and convenience sampling techniques were applied to managers and employees respectively. The findings of the study revealed that HR practices are improperly planned; implemented and managed by non-HR experts and that the practices, programs and policies of these rural banks are lowly perceived by their employees. The study also showed that the enormous benefits of properly managing human resources are lost to these rural banks. It was recommended that rural banks should dedicate a department to HR for the proper management of human resources through whom competitive advantage could be created (Quansah, 2013).

After reviewing these articles, most of the researchers found that proper human resource management practices have positive relationship with organizational performance, in terms of using proper recruitment and selection, compensation and reward, employment security, especially the contribution of (Abdulla et al., 2009). Regression results showed that training and development, team work, compensation/incentives, HR planning, performance appraisal, and employees security have positive and significant influence on business performance with the exception for compensation/incentives and employees security. However its further research is 
needed to make clear the role of human resource management practice on organizational performance in order to know deeply the relationship between Human Resource Management Practice and Organizational Performance. The researcher generated the following hypothesis in order to test the relationship between human resource management and organizational performance.

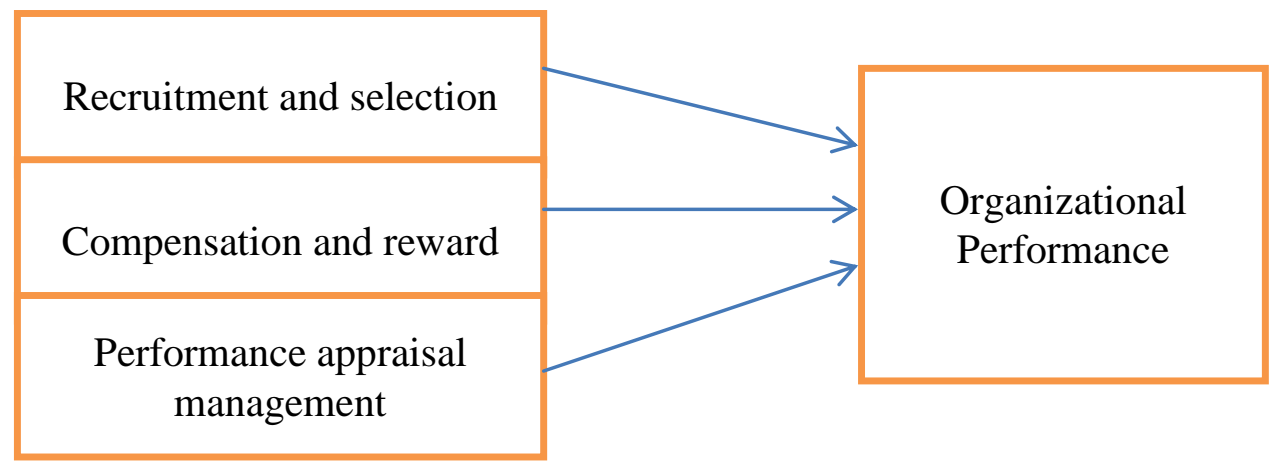

H1: there is positive relationship between recruitment and selection with organizational performance at Hormuud Telecom in Mogadishu-Somalia

H2: there is positive relationship between compensation and reward with organizational performance at Hormuud Telecom in Mogadishu-Somalia.

H3: there is positive relationship between performance appraisal and management with organizational performance at Hormuud Telecom in Mogadishu-Somalia.

\section{Methodology}

This study was conducted through case study method to examine the role of human resource management practice on organizational performance at Hormuud Telecom in Mogadishu-Somalia. The study utilized regression, correlation analysis to answer the research objectives and to test the research hypothesis.

The researchers utilized convenient sampling to collect 100 employees from Hormuud Telecom in Mogadishu-Somalia. These respondents were provided a questionnaire with four main construct which measuring recruitment and selection, compensation and reward, performance appraisal management as well as organizational performance. The researchers' utilized Cronbach alpha to investigate the internal consistency of the questionnaires collected from the respondents. All variables of the study gained high inside reliability as shown in below Table 1 this allows as to make further analysis and discussion.

Table 1. Reliability test

\begin{tabular}{|l|c|c|}
\hline Variables & Items & Cronbach Alpha \\
\hline Recruitment selection & 5 & 0.790 \\
\hline Compensation and reward & 4 & 0.770 \\
\hline $\begin{array}{l}\text { Performance appraisal } \\
\text { management }\end{array}$ & 5 & 0.765 \\
\hline \begin{tabular}{l} 
Organizational performance \\
\hline
\end{tabular} & 9 & 0.806 \\
\hline
\end{tabular}

\section{Data Analysis and Discussion}

\section{Demographic Profile}

According to the gender respondents $93.0 \%$ were male while $7.0 \%$ was female. $69.0 \%$ of the respondent's age was between 20-30 years old, $26.0 \%$ was between 31-40 years, 2.0 \% was between 41-50 years while $3.0 \%$ were above 51 years. In terms of marital status of the respondents, $54.0 \%$ were married while $46.0 \%$ were single. In terms of educational background $4.0 \%$ were 
secondary level, $20.0 \%$ of the respondents had diploma certificate, $65.0 \%$ of the respondents were bachelor degree, and $10.0 \%$ were master degree level while 1.0\% had other certificate. In terms of experience $19.0 \%$ of the respondents had one year experience, $29.0 \%$ of the respondents had two years' experience, $24.0 \%$ of the respondents had three years' experience while $28.0 \%$ of the respondents had more than three years experience. In terms of occupation of the respondents, $35.0 \%$ of the respondents were employee/staff, $35.0 \%$ of the respondents were managers, and $4.0 \%$ of the respondents were security while $26.0 \%$ were other people.

Table 2. Demographic of the respondents

\begin{tabular}{|l|l|l|}
\hline Variables & Frequency & Percentage \\
\hline Gender & & \\
\hline Male & 93 & 93.0 \\
\hline Female & 7 & 7.0 \\
\hline Total & $\mathbf{1 0 0}$ & $\mathbf{1 0 0 . 0}$ \\
\hline Age & & \\
\hline $20-30$ Years & 69 & 69.0 \\
\hline $31-40$ Years & 26 & 26.0 \\
\hline $41-50$ Years & 2 & 2.0 \\
\hline 51 and above & 3 & 3.0 \\
\hline Total & $\mathbf{1 0 0}$ & $\mathbf{1 0 0 . 0}$ \\
\hline Marital status & & \\
\hline Single & 46 & 46.0 \\
\hline Married & 54 & 54.0 \\
\hline Total & $\mathbf{1 0 0}$ & $\mathbf{1 0 0 . 0}$ \\
\hline $\begin{array}{l}\text { Education Background } \text { of } \\
\text { respondents }\end{array}$ & & \\
\hline High school level & 4 & 4.0 \\
\hline Diploma level & 20 & 20.0 \\
\hline Bachelor Degree & 65 & 65.0 \\
\hline Master degree & 10 & 10.0 \\
\hline others & 1 & 1.0 \\
\hline Total & $\mathbf{1 0 0}$ & $\mathbf{1 0 0 . 0}$ \\
\hline Experience of the respondents & & \\
\hline One year & 19 & 19.0 \\
\hline Two years & 29 & 29.0 \\
\hline Three years & 24 & 24.0 \\
\hline Above three years & 28 & 28.0 \\
\hline Total & $\mathbf{1 0 0}$ & $\mathbf{1 0 0}$ \\
\hline Occupation of the respondents & & \\
\hline Employee/staff & 35 & 35.0 \\
\hline Manager & 35 & 35.0 \\
\hline Security & 4 & 4.0 \\
\hline Others & 26 & 26.0 \\
\hline Total & $\mathbf{1 0 0}$ & $\mathbf{1 0 0 . 0}$ \\
\hline & & \\
\hline & & \\
\hline & & \\
\hline
\end{tabular}

\section{Correlation between the Variables}

Table 3 shows the result of correlation analyzes of the relationships among recruitment selection, compensation and reward, performance appraisal management and organizational performance at Hormuud Telecom in Mogadishu-Somalia. Recruitment selection has positive relationship with organizational performance $(\mathrm{r}=.594$ and $\mathrm{p}<0.01)$. Recruitment and selection plays good role in the organizational performance. The second objective of this study was to identify the relationship between compensation and reward with organizational performance. Compensation and reward has positive relationship with organizational performance $(\mathrm{r}=.664$ and $\mathrm{p}<0.01$ ). The third objective was to examine the relationship between performance appraisal management with organizational performance at Hormuud Telecom in Mogadishu-Somalia. 
Performance appraisal management has positive relationship with organizational performance $(\mathrm{r}=.663$ and $\mathrm{p}<0.01)$.

Table 3. Correlation Analyzes

\begin{tabular}{|l|l|l|l|l|l|l|l|}
\hline No & Variables & Mean & SD & $\mathbf{1}$ & $\mathbf{2}$ & $\mathbf{3}$ & $\mathbf{4}$ \\
\hline 1 & $\begin{array}{l}\text { Recruitment and } \\
\text { selection }\end{array}$ & 3.7640 & .95235 & 1 & & & \\
\hline 2 & $\begin{array}{l}\text { Compensation and } \\
\text { reward }\end{array}$ & 3.8300 & .86667 & .644 & 1 & & \\
\hline 3 & $\begin{array}{l}\text { Performance and } \\
\text { appraisal management }\end{array}$ & 3.8575 & .84779 & .609 & .722 & 1 & .663 \\
\hline 4 & $\begin{array}{l}\text { Organizational } \\
\text { performance }\end{array}$ & 3.8856 & .64643 & .594 & .664 & .62 \\
\hline
\end{tabular}

\section{Regression Analysis}

This study investigated the role of human resource management practice on organizational performance at Hormuud Telecom in Mogadishu-Somalia. Three hypotheses were developed after reviewing the literature, to test the research hypotheses were employed the linear regression analysis. The researchers checked regression hypothesis before taking place to further analysis. The dependent variable which is organizational performance was normally distributed across all independent variable. Three hypotheses were developed after reviewing the existing literature; H1 confirmed that there is positive relationship between recruitment and selection with organizational performance at Hormuud Telecom in Mogadishu-Somalia. H2 asserted that there is positive relationship between compensation and reward with organizational performance, While H3: there is significant relationship between performance appraisal management and organizational performance at Hormuud Telecom in Mogadishu, Somalia.

Table 4. Regression Analysis

\begin{tabular}{|l|l|l|l|l|}
\hline Variables & Beta & t-value & Significant & Results \\
\hline Recruitment and selection & .206 & 2.176 & .032 & H1 Accepted \\
\hline Compensation and reward & .299 & 2.757 & .007 & H2 Accepted \\
\hline Performance and appraisal management & .321 & 3.069 & .003 & H3 Accepted \\
\hline R & .731 & & \\
\hline R Square & .534 & & \\
\hline Adjusted R Square & .519 & & \\
\hline
\end{tabular}

\section{Discussion}

The current study investigated the role of human resource management practice on organization performance at Hormuud in Mogadishu-Somalia; the paper had three main objectives which are: 1) to determine the influence of recruitment and selection on organizational performance. 2) To identify the impact of compensation and reward on organizational performance. 3) To examine the role of performance appraisal management on organizational performance at Hormuud Telecom in Mogadishu-Somalia. The researchers employed convenient sampling to collect 100 respondents from Hormuud Telecom in Mogadishu. The result of correlation coefficient revealed that organizational performance (Dependent variable) had significant positive influence with three independent variables namely: recruitment and selection, compensation and reward as well as performance appraisal management. The result of regression analysis found that two constructs had statistically significant, positive, and direct effect on higher education. Human resources are vital for firms to achieve advanced innovations and sustainable performance in the ever-changing environment. The standpoint of this study emphasizes the important role of innovation performance and environmental performance when addressing the link between human resource management and organizational performance. Subsequently, incorporation of green element in HRM will certainly enhance sustainable improvements which benefit long term organizational performance. 


\section{Conclusion}

Human resources are vital for firms to achieve advanced innovations and sustainable performance in the ever-changing environment. The standpoint of this study emphasizes the important role of innovation performance and environmental performance when addressing the link between human resource management and organizational performance. Subsequently, incorporation of green element in HRM will certainly enhance sustainable improvements which benefit long term organizational performance.

The research article is mentioning the reviews of different researchers from books, research articles, thesis, and other literature available on internet. It includes various perspectives and perceptions of varies researchers regarding the relationship between HRM practices and Organizational Performance. They found that there exists a link or association between different HRM practices and organizational performance. Thus this is a well-researched and well discussed topic worldwide.

\section{References}

Abdullah et al., 2009 - Abdullah, Z., Ahsan, N., \& Alam, S. S. (2009). The Effect of Human Resource Management Practices on Business Performance among Private Companies in Malaysia. International Journal of Business and Management, 4(6), 65-72.

Ahmad, Shahzad, 2011 - Ahmad, S., \& Shahzad, K. (2011). HRM and employee performance: A case of university teachers of Azad Jammu and Kashmir (AJK) in Pakistan. African Journal of Business Management, 5(13), 5249-5253.

Al-bahussin et al., 2013 - Al-bahussin, S. A., El-garaihy, W. H. (2013). The Impact of Human Resource Management Practices,Organisational Culture, Organisational Innovation and Knowledge Management on Organisational Performance in Large Saudi Organisations: Structural Equation Modeling With Conceptual Framework. International Journal of Business and Management, 8(22), 1-19.

Arshad et al., 2014 - Arshad, A., Azhar, S. M., \& Khawaja, K. J. (2014). Dynamics of HRM Practices and Organizational Performance: Quest for Strategic Effectiveness in Pakistani Organizations. International Journal of Business and Social Science, 5(9), 93-101.

Cania, 2014 - Cania, L. (2014). The Impact of Strategic Human Resource Management on Organizational Performance. Economia. Seria Management, 17(2), 374-383.

Dele et al., 2015 - Dele, A. O., Nanle, M., \& Ozioma, A. V. (2015). Strategic Human Resource Management and Organizational Performance in the Nigerian Oil and Gas Industry: The Mediating Role of Organizational Climate. International Journal of Investment Management and Financial Innovations, 1(3), 56-68.

Hassan, 2016 - Hassan, S. (2016). Impact of HRM Practices on Employee's Performance. International Journal of Academic Research in Accounting, Finance and Management Sciences, 6(1), 15-22.

Katou, 2008 - Katou, A. A. (2008). Measuring the impact of HRM on organisational performance. Journal of industrial engineering and management, 1(2), 119-142.

Quansah, 2013 - Quansah, N. (2013). The impact of HRM practices on Organizational performance: the case study of some selected Rural Banks. International Journal of Management, 1-145.

Rhee, 2014 - Rhee, J., Zhao, X., \& Kim, C. (2014). Effects of HRM Practices on Chinese Firms' Organizational Performance: The Moderating Effect of CEO Support. Asian Social Science, 10(13), 210-221.

Trivedi, Raval, 2015 - Trivedi, S., Raval, D. (2015). Review of Literature on the Study of Linkage between Human Resource Management Practices and Organizational Performance. International Journal of Advance Research in Computer Science and Management Studies, 3(6), 314-323.

Wong et al., 2013 - Wong, K.-L., Tan, P.S.-H., Ng, Y.-K., \& Fong, C.-Y. (2013). The Role of HRM in Enhancing Organizational Performance. Human Resource Management Research, 3(1), 11-15. 